\title{
Quality Management and Audit Process in Aviation Organizations
}

\author{
Ebru YAZGAN
}

\begin{abstract}
All areas in the aviation industry such as maintenance, airport, pilot and maintenance training compliance with national and/or international legislation is extremely important. Operation and training activities in aviation must perform within the framework of similar arrangements all around the world. In other words, aviation organizations cannot perform their operations and trainings except aviation legislation defined with international law. Therefore organizations should ensure the establishment and functioning of quality management system to monitor compliance to the requirements of aviation legislation. Requirements regarding the quality system are given in many aviation legislation. Quality management system audits are conducted to ensure compliance with legislation and investigate the weaknesses of the system in aviation organizations. In this study, it will be explained that how method related to auditing and audit management process in aviation organizations should be followed. However, in this study, flowchart of quality system audits is developed in flight training organization.

The audit process is split into two separate stages. The audit and the corrective action phase. Correction action is taken in response to an audit finding in audit management. Besides, in this study, flowchart of corrective action phase is developed in flight training organization. It is aimed that these flowcharts about audits and corrective action are the basic guidance for aviation organisations.
\end{abstract}

Index Terms - Quality Management, Aviation, Audit Process, Flowchart, Flight Training Organization.

\section{INTRODUCTION}

\section{A. Quality Management}

Quality is primarily a competitive tool. In the 21 st century tehre is no doubt that organizations that understand and make use of the fundemantel principles of quality and quality management can gain tremendous competitive advantage and grow a profitable business. Quality management is the means by which an organisation ensures that it's products and/or services meet company,customer and regulatory requirements. It is combination of resources, responsibilities and actions that together ensure that specified requirements are met. It is combination of systematic approaches to doing he work, together with specific checks to ensure that the work has been undertaken correctly [1].

Aircraft maintenance, airport, air traffic controller, pilot and maintenance training compliance with national and/or international legislation is extremely important. Aviation

Ebru YAZGAN is with Faculty of Aeronautics and Astronautics, Anadolu University, Iki Eylul Campus, 26470, Turkey organizations must carried out their operation and training activities in accordance with all applicable international standarts to ensure flight safety and airworthy aeroplanes. In other words, in aviation organizations the quality management system permits the entity to monitor compliance with national/international regulations and all other standards which introduced by aviation authorities in order to ensure the continuation of flight and ground safety operations and the continuing airworthiness of aircraft.

Aviation organizations should monitor comply with regulatory requirements by doing following:

- to establish and maint quality management system

- to provide feedback system to the Accountable Manager

- to constitute a quality assurance programme

- to identify all quality and operation producers in manuals.

Quality assurance is the means of quality management focused on providing confidence that quality requirements will be fulfilled [2]. Quality assurance includes the application of quality systems, in the form of written procedures,coupled with specific (and necessary) quality control checks, all designd to ensure that products and/or services meet defined specifications and satisfy customer expectations [1].

Annual quality assurance programs are created by the Quality Management Department in order to systematically perform quality audits. The Quality System is required to make progress in the following topics:

- Leadership of management

- Creating policies and strategies

- Determination of operational processes

- Implementation of regulatory requirements

- Creating and monitoring organisational structure

- Determination of establishment, development and management responsibilities of quality management system

- Controlling of all documents including manuals, reports and records

- Creating quality management system programme

- Providing and analyzing required financial, material and human resources

- Measuring customer satisfaction (for intenal and external )

- Providing feedbacks to the senior management

- Creating required documents 
- Performing quality system audits

- Determination of areas and subjects to be audited

- Monitoring corrective activities

- Evaluation of management

- Establishing a record system

- Controlling subcontractors (if there is)

- Training quality management system personnel

\section{B. Basic Principles of Auditing}

An audit is a systematic, independent and documented process for obtaining audit evidence and evaluating it objectively to determine the extent to which audit criteria are fulfilled [3].

Auditing's are not undertaken merely to ensure regulatory compliance, but to search out weaknesses in the management system. The auditing process is there to serve the needs of management, to provide them with feedback on systems implementation and effectiveness and providing objective data to assist in decision making. For the audit process to function effectively it needs to be managed. Audit management is a key responsibility. We need to ensure that both the audit process and the auditors themselves are aligned to business needs. Auditing provides the feedback mechanism which tells us how well our systems are functioning and where improvements could be made. Today, auditing is recognized as an extremely powerful technique that may be used by managers alongside other management techniques to ensure adequacy of operations and assist in the achievement of objectives, it has become part of the overall process of business management [1].

\section{The Audit Process}

Although every audit project is unique, the audit process is similar for most engagements and normally consists of four stages: Planning (sometimes called Survey or Preliminary Review), Fieldwork, Audit Report, and Follow-up Review [4].

Audits should be undertaken when there is a need for information in order to facilitate decision making. In many cases, particularly for internal audits, it is the auditors themselves who decide what should be audited and how frequently. This is clearly an inadequate approach, however if management take little or no interest in auditing then it is inevitable that those who appreciate the need, ora re enthusiastic about the task will drive the process in the way that they feel best serves the need of the organisation. The end result is an audit system that providesinformation about aspects of organisational performance that are of little or no concern by senior management, whilst important aspects are left un-investigated. There are two seperate sub processes in relation to any auditing activity:

1. The audit itself-gathering information for the auditor's client

2. The corrective action process-which is driven by the client and may not even involve the auditor.

In regulated aviation organisations the Accountable Manager is the auditor's client and it is noted that many regulations require a feedback mechanism to ensure that the audit results are conveyed to the Accountable Manager, not necessarily as individual findings bu possibly in the form of a trend analysis identifying significant weaknesses in the quality management system, processes or individual products or services. Also, in many regulations the responsibility for managing the audit process is identified as a responsibility of the Quality Manager [1]. Frame of Audit management is given Figure 1.

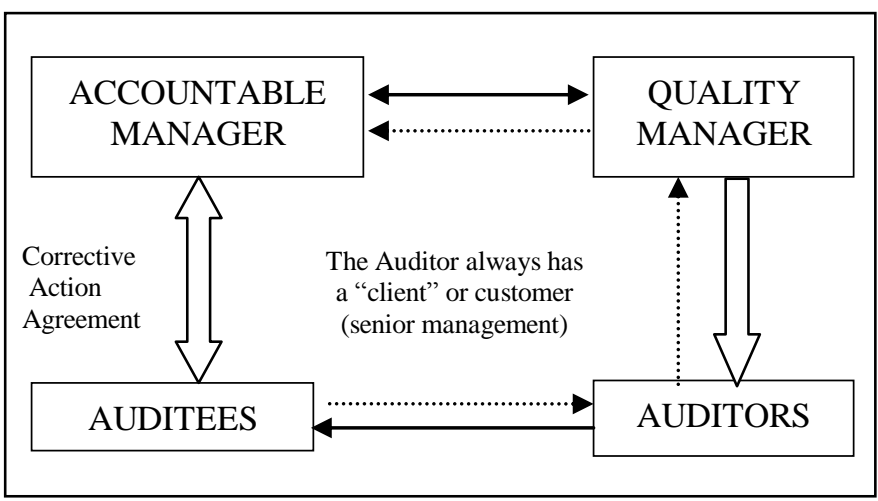

Fig.1 Frame of Audit management [1]

It is the responsibility of Audit Management to liaise with the client and determine what are the audit needs of the client. It is then possible to programme audits to provide this information and arrange for suitable audit resources. It must be recognised that for certain information auditors with very specialist knowledge and experience may be required. Once the audits have been undertaken and the information provided to the client, it is then the responsibility of the client to decide if corrective action is neccessary and by when. They Will either need to liase directly with the audited functions or request the auditors to undertake this task on their behalf [1].

In this study, flowchart of quality system audits is developed in flight training organization. This flowchart and detail explanations is given in Appendix 1.

This quality audits flow chart has been developed by taking the opinions of experts in aviation sector and the experience of the quality department employees in Flight Training Organization (FTO). This flow chart to make audits show the procedure to be followed not only for the FTOs but also for all aviation organizations.

\section{Corrective Action and Remedial Action}

An aspect of auditing that is not often fully addressed in regulations is the need to ensure that "Corrective Action" (action to adress the underlying cause of the problem) is taken in response to an audit finding.

There are two separate actions that often need to be taken in response to an audit finding. The first action is the immediate fixing of the problem- this is termed "Remedial Action" and is the action that will elimintae/remove the problem. However audits often only reveal the 'symtom' of a fundemantal process weakness or process breakdown, and it is necessary to identify what has caused this breakdown and then by fixing it the process will not break down in the future and hence further instances of what has found by the audit 
will be avoided [1]. Description of Corrective Action and Remedial Action is given Figure 2.

Remedial acton 'fixes' the problem, but does not correct
the process weakness

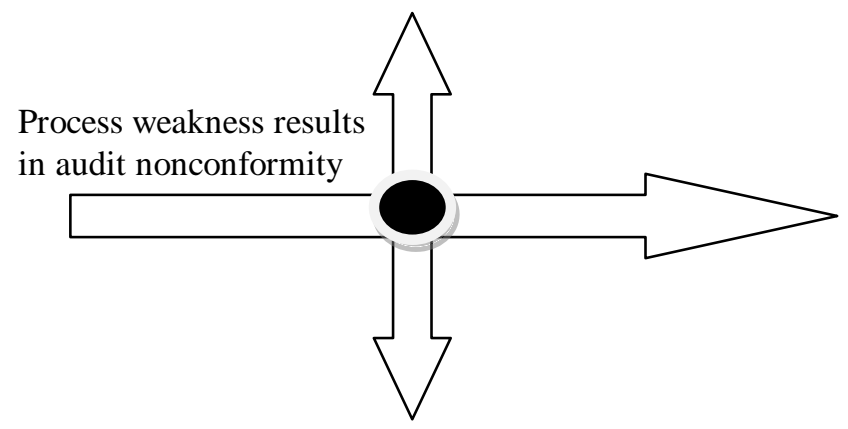

Coorective action 'corrects' the process weakness and prevents further failures

Fig.2 Description of Corrective Action and Remedial Action [1]

"Corrective action" means an action to eliminate the cause of a finding of non-conformity with the applicable requirements in order to prevent recurrence. The competent authority shall report to the Agency in due time on the completion of corrective actions and provide evidence thereof [5].

It is recommended that the audit life cycle is split into two processes. The audit itself and the corrective action phase. Auditee management are fully responsible for the determination and implementation of appropriate corrective action in a timely manner to ensure that system weaknesses are rectified as soon as practicable. Audit management need to be satisfied that corrective action is taken and effective, this should be formally recorded and the audit 'closed out'. This check on the effectiveness of the corrective action is aimed at establishing that the root cause of the problem has been addressed and the problem ('symptoms') found on the initial audit is no longer evident. This will require appropriate audit samples to check for the problem previously noted in appropriate areas of the organization. It may be useful to check the ongoing effectiveness of any corrective actions again at subsequent audits [1].

A corrective action is a reaction to a problem that has already occurred. The actions initiated are intended to: a) fix the problem and b) modify the quality system so that the process that caused it is monitored to prevent a reoccurrence. The documentation for a corrective action provides evidence that the problem was recognized, corrected, and proper controls installed to make sure that it does not happen again [6].

A Preventive Action is a proactive approach and process for detecting non-conformances or undesirable situations that have not yet happened and prevents them before occurring. The process includes:

- Identify potential problems or non-conformances
- Find the cause of the potential problem / non conformance

- Develop a plan to prevent the occurrence

- Implement the plan

- Review the actions taken and the effectiveness in preventing the problem [7].

In this study, flowchart of Corrective Action and Remedial Action Phase is developed in flight training organization. This flowchart and detail explanations is given in Appendix 2.

This the request and tracking of corrective and remedial action flow chart has been developed by taking the opinions of experts in aviation sector and the experience of the quality department employees in Flight Training Organization (FTO). This flow chart to make the request and tracking corrective and remedial action show the procedure to be followed not only for the FTOs but also for all aviation organizations.

\section{CONCLUSION}

At the end of the study, improvement of the flowcharts about quality audits and corrective, remedial action shall guide aviation organizations that have to make quality management system audits. Since the requirements of national or international instructions are excessive, flight traininig organizations experience too serious difficulties in audit period. By using the flowcharts to be improved in this study by aviation organizations; difficulties of excess and complex instructions necessary to follow are aimed to be removed and audit periods are aimed to be reduced. This study may leading for both other departments and organizations.

Consequently, flowcharts for the procedures to be followed by has been put forward. While forming the flowcharts, all relevant activities necessary to make quality audits has been investigated and expert opinions has been taken. Thus the results of this study shall constitute a guide for both flight training organizations and other aviation organizations.

With this study is to emphasize the importance of quality management system audits for aviation organizations by improving flowcharts. Also this study aims to increase the situational awareness about quality management system for aviation organizations.

\section{APPENDIX}

Flowchart of quality system audits for flight training organization is given in Appendix 1.

Flowchart of Corrective Action and Remedial Action Phase for flight training organization is given in Appendix 2. 
Appendix 1: Quality System Audits Flow Chart

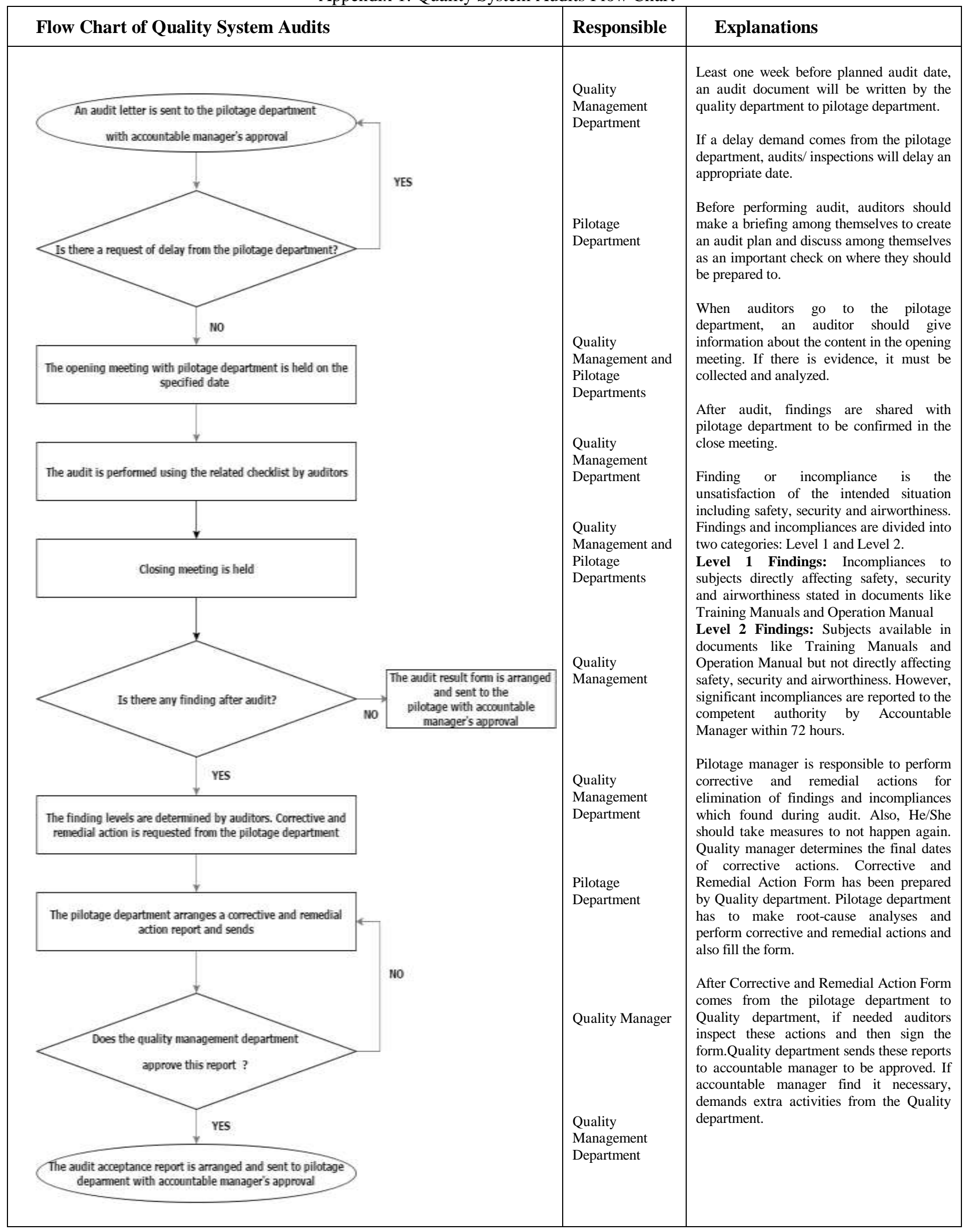


Appendix 2: The Request and Tracking of Corrective and Remedial Action Flow Chart

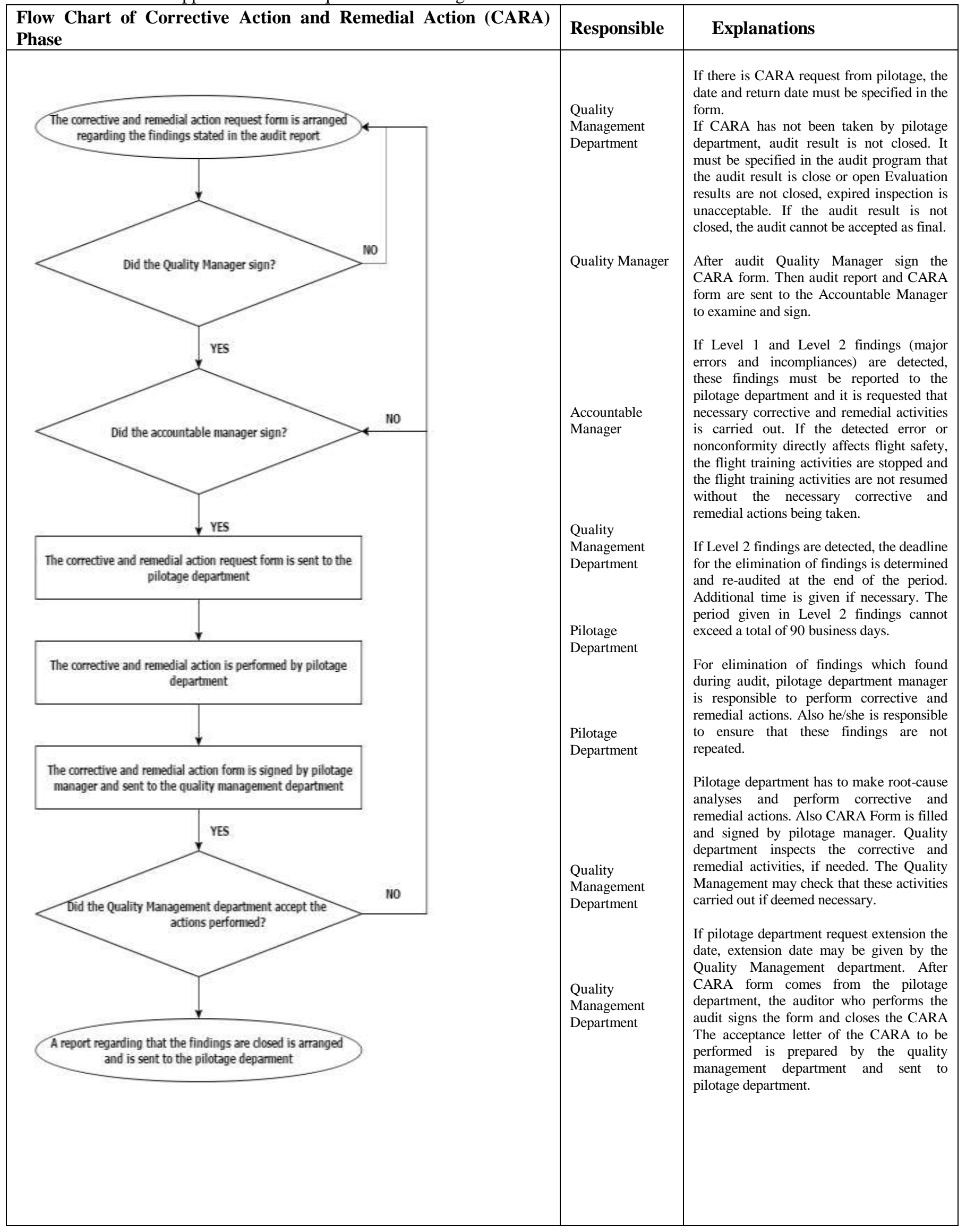




\section{ACKNOWLEDGMENT}

I thank to Musab AYDIN and Fatih KATIRCIOGLU for the writing stage. I also thank to Mustafa TOPAL for the development of flowcharts stage.

\section{REFERENCES}

[1] Joint Aviation Authorities (JAA), (2013). Quality management - principles $\&$ practice in an aviation environment.

[2] ISO 9000:2005, Clause 3.2.11.

[3] http://asq.org/public/auditing-qms-p1.pdf.

[4] https://www.auditnet.org/audit-library/the-internal-audit-process-from-a-toz-how-it-works

[5] https://www.caa.co.uk/uploadedFiles/CAA/Content/Standard_Content/Co mmercial_industry/Aircraft/Airworthiness/Seminars/Corporate_aviation_J une_2016/FWM20160629_09_Root\%20Cause\%20Analysis.pdf

[6] http://www.rmbimedical.com/RegulatoryAffairs/capa\%20guidelines.pdf

[7] http://www.sgs.com/en/news/2014/02/capa-management-in-a-gmpenvironment

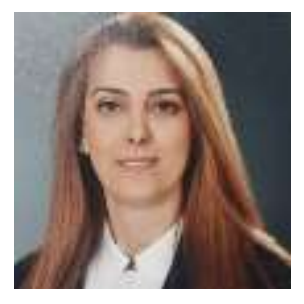

Ebru Yazgan was born in 1977 in Eskisehir. She received her undergraduate degree in the Department of Mechanical Engineering, Istanbul Technical University, Istanbul, Turkey in 1999. She received her Master of Science and $\mathrm{Ph}$. D. degrees in the Department of Industrial Engineering, Eskisehir Osmangazi University, Eskisehir, Turkey in 2005 and 2010, respectively.

She worked in various factories in Turkey as product development engineer and process engineer between 1999-2004. She is now the quality management coordinator and lecturer in Faculty of Aeronautics and Astronautics at Anadolu University, Eskisehir since 2005. She teaches Human Factors, Ergonomics, and Cognitive Ergonomics. Among her research areas are ergonomics, human factors, human error, pilot error and quality. She has published many papers at various national and international journal and conferences. 